\title{
Vitiligo and other hypopigmentation disorders in children and adolescents
}

\author{
Sonja Prćić ${ }^{1}$, Verica Đuran², Dragan Katanić ${ }^{1}$ \\ ${ }^{1}$ Institute for Health Care of Children and \\ Youth of Vojvodina, Medical Faculty of \\ University of Novi Sad, Novi Sad, Serbia \\ ${ }^{2}$ Clinic for Skin and Venereal Diseases \\ Clinical Center of Vojvodina, Medical \\ Faculty of University of Novi Sad \\ Novi Sad, Serbia \\ Corresponding author: \\ Sonja Prćić \\ Institute for Health Care of \\ The loss of pigment, either partial (hypopigmentation) or complete \\ (depigmentation), can have a major psychological impact on patients. \\ Hypopigmentation disorders, congenital and acquired, are very nu- \\ merous, and many of them are rarely seen. This paper provides an \\ overview of the most common hypopigmentation disorders in chil- \\ dren and adolescents, stressing the importance of vitiligo and autoim- \\ mune disorders in patients. Vitiligo is an acquired disease, possibly of \\ autoimmune nature, sometimes with a clear hereditary component, \\ which is characterized by progressive, clearly defined, milky white \\ spots on the skin and/or mucous membranes. In about $50 \%$ of patients \\ vitiligo occurs before 20 years of age. The clinical picture of vitiligo in \\ children and adolescents is similar to adults, but there are some dif- \\ ferences in the epidemiology, their associations with other endocrine \\ and/or autoimmune diseases and treatment of vitiligo in children \\ compared to adult patients.
} Children and Youth of Vojvodina Department of Dermatology 10, Hajduk Veljko St 21000 Novi Sad Serbia buki97@EUnet.rs Tel.: + 381214880444 Fax: + 38121520436

Received: 12 June 2011 Accepted: 4 July 2011

Copyright (C) 2011 by Academy of Sciences and Arts of Bosnia and Herzegovina. E-mail for permission to publish: amabih@anubih.ba
Key words: Hypopigmentation, Vitiligo, Child, Adolescent, Diagnosis.

\section{Introduction}

Pigmentation disorders can be congenital or acquired. Congenital disorders of pigmentation, often result from mutations of many genes that govern the processes of development of melanoblasts, their migratory movements towards the periphery, and their differentiation into mature melanocytes that produce pigment. The acquired pigmentation disorders are mainly due to qualitative or quantitative defects of melanocytes (e.g. vitiligo) in the skin and mucous membrane $(1,2)$.

The loss of pigment, either partial (hypopigmentation) or complete (depigmentation), can have a major psychological impact on patients. In many religious writings, depigmentation is described as a sign of dangerous, communicable diseases (3). In ancient times, vitiligo was equated with leprosy, in which hypopigmentation also occurs, and these patients were varying degrees of social 
outcasts $(1,2,4)$. Although it is now known that most hypopigmented changes in the skin are not contagious and dangerous, loss of pigment causes psychological problems for a large number of patients (5). Many skin diseases are accompanied by hypopigmentation or depigmentation. Vitiligo, pityriasis alba and pityriasis versicolor and varietas alba are seen in everyday clinical practice, and these diseases will be discussed (6).

\section{Vitiligo}

Vitiligo is an acquired disease, possibly autoimmune by nature, sometimes with a clear hereditary component, which is characterized by progressive, clearly circumscribed, milky white spots on the skin and/ or mucous membranes. The name vitiligo comes from the Latin vitium (anomaly) or vitelius (white patches on calf's fur) $(1,2,3)$.

\section{Epidemiology}

Vitiligo occurs among people of all races and climates. It is believed that $1-2 \%$ of the world's population is affected. It can occur in all age groups, but in half the patients it occurs before 20 years of age $(1,2,3,4,7)$. Some authors suggest that $25 \%$ of patients first develop the symptoms before the age of eight, and $50 \%$ of patients prior to 10 years $(7,8,9)$.

The epidemiology of vitiligo in children is similar to adults, but there are certain characteristics of children's vitiligo. Unlike adults, where the frequency of vitiligo in both sexes is about the same, vitiligo in children is more common in girls (10). A family history of associated endocrine and / or autoimmune disease is more common in children with vitiligo than in adult patients. Vitiligo is present in the family history of $12 \%$ to $35 \%$ of affected children, as opposed to about $8 \%$ of adult patients $(7,10,11,12)$.

\section{The etiology and pathogenesis of vitiligo}

The etiology and pathogenesis of vitiligo is not fully explained. It is known that genetic factors play a role in the development of vitiligo: a positive family history in up to $30 \%$ of patients, described cases of vitiligo in twins, and the fact that vitiligo occurs with diseases that have a clear genetic basis, such as diabetes mellitus, suggests that role $(3,4$, 13). Recent research suggests two possible modes of inheritance of vitiligo, which are associated with the age at which vitiligo appeared (14). In patients with early onset of vitiligo (before age 30 ), vitiligo is caused by the dominant mode of inheritance with incomplete penetration. However, in patients with late onset (after age 30), predisposition to vitiligo is the result of a recessive genotype and the influence of the external environment $(15,16)$. An earlier start of vitiligo (up to 7 years) was found in children with vitiligo and a positive family history of vitiligo (17). There is clear evidence of the association of certain MHC haplotypes with a positive family history of vitiligo, onset timing, severity of disease and ethnic origin $(15,16)$. As a possible theory for the etiology of vitiligo the following are cited: the autoimmune, oxidative stress theory (theory of self-destruction of melanocytes) and the neurogenic theory $(1,2,3,4)$.

The autoimmune theory is supported by experimental evidence and clinical association with other autoimmune diseases: pernicious anemia, Addison's disease, type 1 diabetes mellitus (T1DM), juvenile rheumatoid arthritis, alopecia areata and especially Hashimoto's thyroiditis $(1,3,18,19,20,21)$. Vitiligo is relatively common in of autoimmune polyglandular insufficiency syndrome (APS), especially in type I (APS-I), where $25 \%$ of patients have vitiligo (22). Patients with vitiligo often have organ-specific serum autoantibodies, especially antithyroid 
(antithyroglobulin and antibodies against thyreoperoxidase) and antiparietal autoantibodies. Some research suggests that an increased incidence of autoimmune thyroiditis in patients with vitiligo is genetically determined. The locus on chromosome 1 AIS1 (engl. autoimmunity susceptibility), responsible for the tendency to autoimmune responses, particularly for vitiligo, in the presence of other genes (e.g. the main histocompatibility complex localized on the short arm of chromosome 6), combined with exposure to external or internal factors, may mediate in the development of Hashimoto's thyroiditis in patients whose AIS1 is susceptible $(23,24)$. It is known that genes on chromosome $17 \mathrm{p} 13$ contribute to the development of certain autoimmune diseases, which include generalized vitiligo, autoimmune thyroiditis, T1DM, rheumatoid arthritis, psoriasis, pernicious anemia, systemic lupus erythematosus, and Addison's disease. Recent studies describe the NALP1 protein as a gene that regulates the intactness of the immune system. Changes in the DNA sequence in the NALP1 domain, are associated with an increased risk of generalized vitiligo and/or other joint autoimmune diseases, such as autoimmune thyroiditis (25). It is believed that autoimmune mechanisms play a key role in the pathogenesis of non- segmental vitiligo (4).
The melanocytes of active vitiligo reveal an increase in oxidants and antioxidant enzyme deficit, with resultant oxidative damage to melanocytes $(3,26,27)$. The emergence of segmental vitiligo can be best explained by the neurogenic theory according to which the nerve endings release the neurochemical mediators that inhibit melanogenesis or have toxic effects on melanocytes, destroying them. Microscopic examination and ultrastructural investigations in people with segmental vitiligo showed damage to axons and disrupted neuropeptide balance in vitiligo lesions $(27,28)$. As possible provoking factors for the occurrence of vitiligo the following are cited: stress, sun burns, recurrent skin injuries. It is believed that different mechanisms may cause the same phenotype: vitiligo is a heterogeneous disease in terms of etiology $(2,4)$.

\section{Clinical characteristics of vitiligo}

The main change in vitiligo is depigmented macula, usually round or oval-shaped, milky white color, with a diameter of several millimeters to several centimeters $(1,2,3,4)$. The skin surface in vitiligo is smooth. Atypical maculae (artificial) appear at the site of injury, lacerations, friction and burns and are the result of Köebner's phenomenon (1). Vit-

Table 1 Characteristics of non-segmental and segmental vitiligo

\begin{tabular}{lll}
\hline Characteristics & Non-segmental vitiligo & Segmental vitiligo \\
\hline Prevalence (\%) & $72-95$ & $5-8$ \\
Distribution pattern & $\begin{array}{l}\text { Symmetrical, not limited to the } \\
\text { dermatome }\end{array}$ & Unilateral, limited to the dermatome \\
Onset & Any age & Young age \\
Course & $\begin{array}{l}\text { Variable, often new lesions occurring } \\
\text { during life (progressive course) }\end{array}$ & $\begin{array}{l}\text { Initial rapid progression, then the activity of } \\
\text { lesions limited to the period up to 2 years }\end{array}$ \\
$\begin{array}{l}\text { Köebner's phenomenon } \\
\text { Association with autoimmune } \\
\text { diseases }\end{array}$ & $\begin{array}{l}\text { Often present } \\
\text { Etiology }\end{array}$ & Rarely present \\
\hline
\end{tabular}


iligo can occur anywhere on the skin. Predilection sites are around the natural openings - the eyes, mouth, nipples, navel and genitals. In the majority of patients vitiligo lesions first appear on skin exposed to the sun. In vitiligo patients polyosis commonly occurs ("white lock of hair") and halo nevus (Sutton nevus) (3).

Vitiligo can be divided into the non-segmental and segmental forms of the disease $(1,2,4,9)$. In segmental vitiligo depigmented plaques are limited to a dermatome. The characteristics of these two types of vitiligo are given in Table 1. In clinical practice the generally accepted classification of vitiligo is by Kovacs (3). According to this classification, vitiligo is divided into focal, segmental, generalized, acrofacial and universal types, which differ not only morphologically but also in their natural course, response to treatment and prognosis $(1,2,3)$.

\section{The association of vitiligo with other endocrine and / or autoimmune diseases}

Adult patients with vitiligo, especially with the generalized form of the disease, are at increased risk of developing a number of endocrine and / or autoimmune diseases, including thyroid disease, T1DM, pernicious anemia, Addison's disease, rheumatoid arthritis and alopecia areata. Vitiligo can occur before, concurrently or after the occurrence of one or more endocrine and / or autoimmune diseases $(1,3)$. Epidemiological studies, carried out on a large number of children with vitiligo, showed no increased risk of contracting one of these endocrine and / or autoimmune diseases $(10,29,30,31,32)$.

Patients with vitiligo most commonly suffer from thyroid disease (30-40\%), precisely Hashimoto's thyroiditis, then hyperthyroidism, hypothyroidism and GravesBasedow's disease $(1,33,34,35)$. Unlike adults, children and adolescents with viti- ligo demonstrate increased frequency of exclusively Hashimoto's thyroiditis. Considering the fact that vitiligo usually precedes autoimmune thyroiditis, a possible early diagnosis of the latter is possible. It is therefore recommended that children and adolescents with non-segmental vitiligo undergo annual screening for antibodies against thyreoperoxidase (TPO- $\mathrm{Ab}$ ), antithyroglobulin antibodies (Tg- $\mathrm{Ab})$ and thyroid-stimulating hormone (TSH) $(36,37,38)$.

\section{Therapy}

Treatment of vitiligo should be initiated with a consultant dermatologist, after presenting therapeutic possibilities and their effectiveness to the patient. The choice of therapeutic options depends primarily on the age and type of vitiligo patients. In all cases it is necessary to use measures to protect against solar radiation and use photoprotective methods $(1,2,39,40)$.

- Phototherapy. There are two basic forms of generalized vitiligo phototherapy: PUVA (Psoralen + UVA) photochemotherapy using photosensitive drug (8-metoxypsoralen) in combination with UVA radiation (320-400 nm wavelength) and UVB rays of narrow range of wavelengths of $311 \mathrm{~nm}$ (Narrow -band UVB). Targeted laser phototherapy is recommended for focal vitiligo $(2,41,42)$.

- Local corticosteroid therapy: treatment for at least 3 to 4 months (watch for side effects of corticosteroids!) (7).

- Other forms of local therapy (melagenin, calcineurin-inhibitors / pimecrolimus, tacrolimus /, calcipotriol, pseudocatalase) $(43,44,45)$

- Depigmentation (monobenzyl hydroquinone ether and 4-methoxy-phenol as a cream) with extensive and generalized vitiligo only in adults and adolescents (2). 
- Surgical treatment (epidermal grafting obtained by suction, autologous skin graft method, mini-transplantations) is the method of choice for segmental vitiligo in adults and adolescents (46).

- Cosmetic camouflage methods (47).

\section{The differential diagnosis of vitiligo}

The diagnosis of vitiligo is set on the basis of history and the characteristic clinical picture, additional laboratory analysis are rarely needed, skin biopsy even rarer. In children there may be differential diagnostic difficulties in relation to other diseases that are accompanied by hypopigmentation, such as pityriasis alba, pityriasis versicolor varietas alba, post-inflammatory hypopigmentation, piebaldism, morfea, leprosy, tuberous sclerosis, naevus depigmentosus and lichen sclerosus et atrophicus $(4,6)$. A special difficulty for the recognition of vitiligo arises in fair-skinned people, where it is harder to spot hypopigmentation or depigmentation. A Wood's lamp (emitting UV rays with wavelengths of $320-400 \mathrm{~nm}$, with a maximum of $365 \mathrm{~nm}$ ), makes it possible to spot the differences between the complete loss of pigment in vitiligo and various other diseases accompanied by hypopigmentation. Knowing the type of inheritance, the characteristic clinical patterns and symptoms of these diseases is necessary to set an accurate diagnosis of vitiligo $(4,6,11)$.

\section{Pityriasis alba}

Pityriasis alba (PA) is a common, benign, localized form of hypopigmentation, which is more common in children than in adults. In children under 12 years of age, prevalence is between $1.9 \%$ and $5.25 \%(2,48)$.

The etiology and pathogenesis of PA is not clarified. There is a perception that the disease is more common in dark-skinned people. PA is considered a minor form of atopic dermatitis. Recent studies have indicated the frequent occurrence of PA in individuals who sunbathe without using photoprotection, and the onset of PA as a result of frequent sunbathing. In these patients the low levels of serum copper was detected, and it is known that copper plays an important role in the synthesis of tyrosinase, which may explain the hypopigmentation $(6,48)$.

The clinical pattern shows unclearly bordered hypopigmented maculae and pityriasis-like desquamation on their surface. The disease begins with an erythematous plaque with elevated edges and desquamation occurs after several weeks. Hypopigmentation can last from 6 months to 7 years. The course is prolonged in patients with atopic dermatitis. PA is an asymptomatic disease, although there may be mild itching. The changes are mainly localized on the head, neck and upper limbs. The most common localizations are the head, the forehead and cheekbones, and it rarely occurs in periorbital and perioral regions, unlike vitiligo. There is a generalized form of atypical PA, which is more often seen in adults, and the changes are localized to the thorax $(1,2,6,48)$.

The therapy involves emollients and corticosteroid creams of low and moderate potency, which have limited effectiveness. The use photoprotective creams is recommended. After a few months or years the condition spontaneously withdraws. In the extensive form in adolescents and adults PUVA therapy is applied (48).

\section{Pityriasis versicolor alba varietas}

The cause of the disease is Pityrosporum ovale (synonyms: Pityrosporum orbiculare, Malassezia furfur, Malassezia ovalis), part of the normal flora of the skin, which under certain circumstances is transformed from saprophytic yeasts into the mycelal phase and leads to skin diseases. The disease is not contagious and occurs in predisposed peo- 
ple, mostly in areas with a humid and warm climate $(6,49)$.

The clinical picture is presented with café-au-lait or yellowish-brown (versicolor) maculae which are circular, oval or irregular in shape, with unclear edges, up to $1 \mathrm{~cm}$ in diameter, with pityriasis-like desquamation at the surface (apparent after mild curretage of the macula) and with a tendency to confluence in plaques. The maculae have characteristic distribution sites, with localization on the chest, back and upper half of the upper arm, and in children they occur on the head and neck. In immunodeficient conditions, the skin changes have atypical distribution (inverse) and the face, creases and some parts of the limbs are affected. The maculae become hypopigmented after sunbathing (Pityriasis versicolor alba varietas) but hypopigmentation is reversible. An asymptomatic infection is the most common, itching is rarely present. If left untreated, the course becomes chronic and could last for years (49).

Diagnosis is made based on the clinical features and the use of a Wood's lamp, when the yellowish-orange fluorescence of the affected skin is noticed. Native mycological examination with $\mathrm{KOH}$ reveals the characteristic appearance of hyphae and spores ("spaghetti and meatballs") $(6,48,49)$.

Local therapy is the method of choice, and imidazole compounds are advised ( $1 \%$ Econazole, Ketoconazole 2\%) and ciclopiroxolamine in the form of a solution, spray or cream 1-2 times a day for 2-4 weeks. Selenium sulfide $2.5 \%$ shampoo and zinc pyrithione shampoo used once a day (foam should be left on the skin 10 minutes), for two weeks. Residual hypopigmentation lasts a few months after healing, which patients should be warned about. The disease may recur, since Pityrosporum ovale belongs to the normal saprophytic flora of the skin. Systemic therapy is not recommended because Pityrosporum ovale is a normal inhabitant of the skin and cannot be completely removed. For prevention of the disease, a soap is recommended containing $\mathrm{Zn}$ and Se sulfide for washing, with mild friction with keratolytics during the summer months as well as the use of a sulfide shampoo with Se and $\mathrm{Zn}$ pyrithione, once a week $(6,48,49)$.

\section{Piebaldism}

Piebaldism is a rare (incidence is $2.5 / 100000$ ) autosomal dominant disorder caused by the irregular development of melanocytes, which is manifested by the focal absence of melanocytes in the affected skin and hair follicles. The clinical picture is characterized by polyosis and multiple, symmetrical, leukodermic maculae, typically distributed on the sides of the trunk, the anterior abdominal wall and above and below the elbows and knees. Polyosis on the forehead is present in $80-90 \%$ of patients. Unlike vitiligo, piebaldism does not appear on the hands, feet and periorificial areas. Hyperpigmented maculae within amelanotic depigmented areas are typical $(1,2,4)$.

In patients with piebaldism mutations of C-kit proto-oncogene are found, which encodes the transmembrane receptor and tyrosine kinase activity, causing the omission of migration and differentiation of melanoblasts from the neural tube during embryonic development, in the affected skin areas. Phenotypic characteristics are fully formed at birth and permanent, and usually do not spread afterwards $(1,2)$. Therapy is symptomatic and includes photoprotection and allows the use of cosmetic camouflage $(1,2)$.

\section{Tuberous sclerosis}

Tuberous sclerosis is an autosomal dominant determined, multisystemic neurocutaneous syndrome, characterized by the formation of multiple hamartomas usually localized in the skin, brain, heart, kidney, liver and lungs. In $2 / 3$ of the patients the disease is the result of sporadic mutations. The char- 
acteristic triad consists of deafness, mental retardation and cutaneous angiofibromas, and is seen in only $29 \%$ of patients. Early diagnosis is important. At birth or during the first months of life in $97.2 \%$ of patients hypopigmented maculae are observed (3 or more), beige-whitish or yellow-whitish in color. They represent a major diagnostic sign. Ash-leaf spots or spear-like and polygonal maculae, sized 0.5 to $2 \mathrm{~cm}$, localized mainly on the trunk or upper legs are characteristic. Less commonly confetti macula or macula of dermatome schedule are seen. Size can vary from $4 \mathrm{~mm}$ to $12 \mathrm{~cm}$. Later, chagrin plate, facial angiofibromas, periungual fibromas and plaque on the forehead could emerge. Systemic manifestations of tuberous sclerosis fall within the scope of pediatrics $(1,2,4,50)$.

Conflict of interest: The authors declare that they have no conflict of interest. This study was not sponsored by any external organization.

Authors' contributions: Conception and design: SP; Acquisition, analysis, interpretation of data: SP; Drafting the article: SP and DK; Revising it critically for important intellectual content: VD and DK.

\section{References}

1. Ortonne JP, Bahdoran P, Fitzpatrick TB, Mosher DB, Hori Y. Hypomelanoses and hypermelanoses. In: Fitzpatrick TB, Freedberg IM, Eisen AZ, Wolff K, Austen KF, Goldsmith LA, eds. Fitzpatrick's Dermatology in general medicine. 6th ed, New York: Mc Graw-Hill Proffesional; 2003. p. 839-47.

2. Pavlović MD. Poremećaji pigmentacije. U: Karadaglić Đ. Dermatologija. Beograd: Vojnoizdavački zavod; 2000. p. 871-902.

3. Kovacs SO. Vitiligo. J Am Acad Dermatol. 1998;38:647-66.

4. Huggins RH, Schwartz RA, Janniger CK. Vitiligo. Acta Dermatoven APA. 2005;4(14): 137-45.

5. Schmid-Ott G, Kunsebeck HW, Jecht E, Shimshoni R, Lazaroff I, Schallmayer S, et al. Stigmatization experience, coping and sense of coherence in vitiligo patients. J Eur Acad Dermatol Venereol. 2007;46:990-5.

6. Lio PA. Little white spots: an approach to hypopigmented macules. Arch Dis Child Ed Pract. 2008;93:98-102.
7. Halder RM. Childhood vitiligo. Clin Dermatol. 1997;15:899-906.

8. Hurwitz S. Disorders of pigmentation. In: Hurwitz S. Clinical pediatric dermatology. Philadelphia: W. B. Saunders Company; 1993. p.458-60.

9. Janniger CK. Childhood vitiligo. Cutis. 1993;51:25-8.

10. Handa S, Dogra S. Epidemiology of childhood vitiligo: a study of 625 patients from north India. Pediatr Dermatol. 2003;20:207-10.

11. Huggins RH, Schwartz RA, Janniger CK. Childhood vitiligo. Cutis Cutaneous Medicine For The Practitioner. 2007;79(4):277-80.

12. Prcic S, Djuran V, Katanic D. Vitiligo in children and adolescents: a literature review. Serb J Dermatol Venereol. 2010;2(3):95-104.

13. Deng GY, Muir A, Maclaren NK, She JX. Association of LMP2 and LMP7 gnes within MHC with insulin- dependent diabetes mellitus: population and family studies. Am J Hum Gen. 1995;56:528-34.

14. Arcos-Burgos M, Parodi E, Salgar M, Bedoya E, Builes J, Jaramillo D, et al. Vitiligo: complex segregation and linkage disequilibrium analyses with respect to microsatelite loci spanning the HLA. Hum Genet. 2002;110:334-42.

15. Zamani M, Spaepen M, Sghar SS, Huang C, Westerhof W, Nieuweboer-Krobotova L, et al. Linkage and association of HLA class II genes with vitiligo in a Dutch population. Br J Dermatol. 2001;145:90-4.

16. Ando I, Chi HI, Nakagawa H, Otsuka F. Difference in clinical features and HLA antigenes between familial and non-familial vitiligo of non-segmental type. Br J Dermatol. 1993;129:408-10.

17. Pajvani U, Ahmad N, Wiley A, Levy RM, Kundu $\mathrm{R}$, Mancini AJ, et al. The relationship between family medical history and childhood vitiligo. J Am Acad Dermatol. 2006;55(2):238-44.

18. Prahalad S, Kingsbury DJ, Griffin TA, Cooper BL, Glass DN, Maksimowych WP, et al. Polymorphism in the MHC- encoded LMP7 gene: association with JRA without functional significance for immunoproteasome assembly. J Rheumatol. 2001; 28:2320-5.

19. Njoo MD, Westerhof W. Vitiligo. Pathogenesis and treatment. Am J Clin Dermatol. 2001;2(3):167-81.

20. Taieb A. Intrinsic and extrinsic pathomechanismus in vitiligo. Pigment Cell Res. 2000;13 Suppl:841-7.

21. Kemp EH, Waterman EA, Weetman AP. Autoimmune aspects of vitiligo. Autoimmunity. 2001;34:653.

22. Alkhateeb A, Fain RP, Thody A, Bennett CD, Spritz RA. Epidemiology of vitiligo and associated autoimmune diseases in Causian probands and their families. Pigment Cell Res. 2003;16 Suppl:208-14. 
23. Fain PR, Gowan K, La berge GS, Alkhateeb A, Stetler GL, Talbert J, et al. A genomewide screen for generalized vitiligo: confirmation of AIS1 on chromosome $1 \mathrm{p} 31$ and evidence for additional susceptibility loci. Am J Hum Genet. 2003;72:1560-4.

24. Alkhateeb A, Stetler GL, Old W, Talbert J, Unihorn C, Taylor M, et al. Mapping of an autoimmunity susceptibility locus (AIS1) to chromosome 1p31.3-p.32.2. Hum Mol Genet.2002;11:661-7.

25. Jin Y, Mailloux CM, Gowan K, Riccardi SL, LaBerge G, Bennett DC, et al. NALP 1 in vitiligo- associated multiple autoimmune disease. N Engl J Med. 2007;356:1216-25.

26. Passi S, De Luca S, Stancato A, Maggro F, Grandinetti M. Epidermal oxidative stress in vitiligo. Pigment Cell Res. 1998;11:81-5.

27. Gauthier Y, Cario Andre M, Taieb A. A critical appraisal of vitiligo etiologic theories. Is melanocyte loss a melanocytorrhagy? Pigment Cell Res. 2003;16:322-32.

28. Liu PY, Johansson O, Loutz W, Bondesson L. The occurrence of cutaneous nerve endings and neuropeptides in vitiligo vulgaris: a case-control study. Arch Dermatol Res. 1996;288:670-5.

29. Cho S, Kang HC, Hahm JH. Characteristics of vitiligo in Korean children. Pediatr Dermatol. 2000; 17:189-93.

30. Zhi H, Jiang-Bo L, Sui- Sui M, Sen Yang, XueJun Z. Profile of childhood vitiligo in China: an analysis of 541 patients. Pediatr Dermatol. 2006; 23(2):114-6.

31. Al-Mutairi N, Sharma AK, Al-Sheltawy M, NourEldin O. Childhood vitiligo: a prospective hospital-based study. Aust J Dermatol. 2005; 46:150-3.

32. Prcic S, Duran V, Mikov A, Mikov I. Vitiligo in children. Pediatr Dermatol. 2007;24(6):666.

33. Hegedus L, Heidenheim M, Gevril M, Hjalgrim $\mathrm{H}$, Hoiert-Madsen M. High frequency of thyroid dysfunction in patients with vitiligo. Acta Derm Venereol. 1994;74:120-3.

34. Zetting G, Tanew A, Fisher G, Mayr W, Dudczak $\mathrm{R}$, Weissel M. Autoimmune diseases in vitiligo: do antinuclear antibodies decrease thyroid volume? Clin Exp Immunol. 2003;131:347-54.

35. Schallreuter KU, Lemke R, Brandt O, Schwartz R, Westhofen M, Montz R, Berger J. Vitiligo and other diseases: coexistence or true association? Hamburg study on 321 patients. Dermatology. 1994;188:269-75.

36. Iacovelli P, Sinagra J, Paro Vidolin A, Marenda S, Capitanio B, Leone G, et al. Relevance of thyroiditis and of other autoimmune diseases in children with vitiligo. Dermatology. 2005;210:26-30.
37. Kakourou T, Kanaka-Gantenbein C, Papadopoulou A, Kaloumenou E, Chrousous G. Increased prevalence of chronic autoimmune (Hashimoto's) thyroiditis in children and adolescents with vitiligo. J Am Acad Dermatol. 2005;220-3.

38. Prćić S. "Vitiligo i poremećaji funkcije štitaste žlezde kod dece i adolescenata”. Doktorska teza. Novi Sad, Srbija: Medicinski fakultet Univerziteta u Novom Sadu: 2009.

39. Parsad D, Pandhi R, Dogra S, Kumar B. Clinical study of repigmentation patterns with different treatments modalities and their correlation with speed and stability of repigmentation in 352 vitiliginous patches. J Am Acad Dermatol. 2004;50:63-7.

40. Grimes PE. Whites patches and bruised souls: advances in pathogenesis and treatment of vitiligo. J Am Acad Dermatol. 2004;51:85-7.

41. Njoo MD, Bos JD, Westerhof W. Treatment of generalised vitiligo in children with narrow-band (TL-01) UVB radiation therapy. J Am Acad Dermatol. 2000;245-3.

42. Hadi SM. Spencer JM. Lebwohl M. The use of 308-nm excimer laser for the treatment of vitiligo. Dermatol Surg. 2004;140:677-83.

43. Xu AE, Wei XD. Topical melagenine for repigmentation in twenty-two child patients with vitiligo on the scalp. Chinese Med J. 2004;117:199-201.

44. Silverberg NB, Lin P, Travis L, Farley-Li J, Mancini AJ, Wagner AM, et al.. Tacrolimus ointment promotes repigmentation of vitiligo in children: a review of 57 cases. J Am Acad Dermatol. 2004;51:760-6.

45. Gargoom AM, Duweb GA, Elzorghany AH, Benghazil M, Bugrein OO. Calcipotriol in the treatment of childhood vitiligo. Int J Clin Pharmacol Res. 2004;24:11-4.

46. Gupta S, Kumar B. Epidermal grafting for vitiligo in adolescents. Pediatr Dermatol. 2002;19:159-62.

47. Tedeshi A, Dall Oglio F, Micali G, Schwartz RA, Janniger CK. Corrective camouflage in pediatric dermatology. Cutis. 2007;79:110-2.

48. Richie L, Janniger C. Pityriasis alba. Cutis Cutaneous Medicine For The Practitioner. 2005;76:21-4.

49. Nelson MM, Martin AG, Hefernan MP. Fungal diseases with cutaneous involment. In: Freedberg IM, Eisen AZ, Wolff K, Austen KF, Goldsmith LA, eds. Fitzpatrick 's Dermatology in general medicine. 6th ed, New York: Mc Graw-Hill Proffesional; 2003. p. 1989-2034.

50. Schwartz R, Fernandez G, Kotylska K, Jozwiak S. Tuberous sclerosis complex: advances in diagnosis, genetics, and management. J Am Acad Dermatol. 2007:189-202. 